\title{
Behavioral Response of Plum Curculio, Conotrachelus nenuphar, to Synthetic Fruit Volatile Lures and the Male-Produced Aggregation Pheromone
}

\author{
Clement Akotsen-Mensah ${ }^{1,2}$ and Henry Y. Fadamiro ${ }^{1}$ \\ ${ }^{1}$ Department of Entomology and Plant Pathology, Auburn University, 301 Funchess Hall, Auburn, AL 38649, USA \\ ${ }^{2}$ Forest and Horticultural Crops Research Centre, School of Agriculture, College of Basic and Applied Sciences, University of Ghana, \\ P.O. Box LG 25, Legon, Accra, Ghana
}

Correspondence should be addressed to Clement Akotsen-Mensah; nimako60@gmail.com

Received 26 July 2015; Revised 7 October 2015; Accepted 15 October 2015

Academic Editor: Jan Klimaszewski

Copyright @ 2015 C. Akotsen-Mensah and H. Y. Fadamiro. This is an open access article distributed under the Creative Commons Attribution License, which permits unrestricted use, distribution, and reproduction in any medium, provided the original work is properly cited.

\begin{abstract}
Plum curculio, Conotrachelus nenuphar Herbst (Coleoptera: Curculionidae), is a key pest of stone and pome fruits in North America. The behavioral response of adults of different physiological states (sex, age, diet, and mating status) to three commercially available synthetic lures, benzaldehyde (BZ) and plum essence (PE), the male-produced aggregation pheromone, grandisoic acid (GA), or their combinations, was studied in the laboratory. Four choice olfactometer bioassays demonstrated significant attraction of both sexes to PE lure. Both BZ and GA lures were not attractive to plum curculio when tested as commercially formulated. PE had higher release rate $(1.51 \mathrm{mg} / \mathrm{hr})$ than BZ $(0.36 \mathrm{mg} / \mathrm{hr})$ and GA (ca. $0.04 \mathrm{mg} / \mathrm{hr})$, suggesting that the higher attractiveness of PE may be due to its relatively higher release rates. Tests with combined lures showed a neutral effect of combining GA with PE and an inhibitory effect of combining BZ with PE. The physiological conditions of the weevils had no significant effect on their response to the lures. Olfactometer tests with pure 1,2,4-trichlorobenzene (TCB) confirmed that this compound was inhibitory to plum curculio. These results are discussed in relation to the contrasting field reports which implicated BZ $+\mathrm{GA}$ as an effective attractant for plum curculio.
\end{abstract}

\section{Introduction}

Plum curculio, Conotrachelus nenuphar (Herbst) (Coleoptera: Curculionidae), is a major pest of many stone and pome fruit crops, which is widely distributed over the United States (U.S.) and Canada, east of the Rocky Mountains [1-4]. It is the most important direct pest of peaches (Prunus persica L.) in the southeastern U.S. [5-9]. Adult weevils typically overwinter in wooded lots adjacent to orchards or around fence rows from where they immigrate into peach orchards in the spring beginning around bloom [7, 10-12]. Like many insects, plum curculio uses olfactory cues, specifically host fruit derived volatiles, to locate host fruit [13-19]. Earlier studies identified several active compounds from host plants (both fruiting and nonfruiting parts) which are attractive to plum curculio $[16,17,20,21]$. To date, the most attractive plant-based volatiles for plum curculio are benzaldehyde (BZ) and foliar and woody tissue of plum trees [16, 21, 22]. Benzaldehyde has since been formulated as an attractant for plum curculio and is commercially available as a lure. Plum essence (PE), a commercially available synthetic mixture of plant essence, is also an attractant for plum curculio [23, 24]. The male-produced aggregation pheromone of plum curculio, grandisoic acid (GA), which was identified by [25], was later shown to act synergistically with BZ to increase adult trap captures in the field [26, 27]. Consequently, a combined lure consisting of $\mathrm{BZ}$ and GA was developed in Massachusetts, in USA, [26] and Quebec, in Canada, and remains to date the most widely used attractant for monitoring plum curculio in orchards $[22,26,28-30]$. The attractiveness of benzaldehyde + GA has, however, been shown to be consistently high in apple orchards in the Northeast but 
less so in peach orchards in the mid-Atlantic region [29]. Also, captures of weevils in traps baited with this combined lure or other synthetic attractants can decline rapidly after fruit set due to intense competition from volatiles released by rapidly developing fruit $[18,29]$. A recent study in Alabama peach orchards showed that captures of plum curculio in pyramid (also called Tedders trap) and "Circle" or screen traps (the two most popular traps for plum curculio) were improved numerically by the addition of $\mathrm{BZ}, \mathrm{PE}$, or GA alone (single lures) and were significantly enhanced only by the addition of the combined BZ + PE lure [9]. The popular combined $\mathrm{BZ}+\mathrm{GA}$ lure was significantly less attractive than the combined BZ + PE lure. The results suggested an additive interaction between BZ and GA, in contrast to the synergistic interaction reported in Massachusetts apples $[26,30]$. These varying results on lure performance may be related to several factors including the type of insect (strains), physicochemical properties of the lures, and differential attractiveness of tree fruit species/varieties, prevailing orchard conditions, strain differences, and physiological state of weevils. Two strains of plum curculio, namely, the northern and southern strains, are known to occur in continental North America. The northern strain has an obligate adult reproductive winter diapause, with one generation per year, whereas the southern strain weevils are multivoltine, with a facultative diapause. There is, therefore, the possibility that the olfactory response of adult plum curculios to synthetic lures may vary according to strain type (e.g., pheromone components produced by southern and northern strain plum curculios might differ). Also, the response to synthetic lures might differ depending on the habitat. For example, the response of plum curculio to synthetic lure has been studied mostly in peach orchards in the south and in apple orchards in the north (e.g., Massachusetts and Quebec). Also the physiological state of insects is known to play a major role in their response to odor cues [31-34]; however, we are not aware of any published studies on the response of plum curculio of different physiological states to currently available lures. This research was therefore designed to evaluate effects of physiological factors on the response of plum curculio to commercial lures. Specifically, we evaluated the response of weevils of different physiological status (sex, age, diet, and mating) to single and combined lures of BZ, PE, and GA in laboratory olfactometer bioassays. Based on the knowledge of the field ecology and spring and summer migration of plum curculio from overwintering sites, we tested the following key hypotheses: (i) females will show greater response to the lures than males, (ii) younger (preoviposition adults) weevils will show greater response to the lures than older (oviposition-postoviposition) weevils, (iii) starved weevils will show greater response to the fruit-based lures (BZ and PE) than fed weevils, and (iv) mating will have no significant effect on response of weevils to the lures. Next, the release rates of the lures were determined gravimetrically and used to provide explanations for the results recorded in the olfactometer bioassays. It is hoped that the results of this laboratory study will assist with the interpretation of field data on captures of plum curculio in traps baited with these lures.

\section{Materials and Methods}

2.1. Test Insects. The colony of plum curculio adults used for this study was maintained on pesticide-free green thinning apples in a growth chamber at $25 \pm 1^{\circ} \mathrm{C}, 65-70 \% \mathrm{RH}$, and $12: 12 \mathrm{~h}(\mathrm{~L}: \mathrm{D})$ photoperiod. The weevils used to start the laboratory colony were collected from peach orchards in central Alabama and had been reared for more than 10 generations before the tests. The colony was periodically supplemented with weevils collected from the same field locations in Alabama. The rearing procedures followed that of $[35,36]$. Females and males were separated using the methods of [37] and then tested separately.

2.2. Lure Treatments. The lures evaluated were commercial liquid formulations of benzaldehyde (BZ), plum essence (PE), and grandisoic acid (GA). The BZ and PE lures were obtained from Great Lakes IPM (Vestaburg, MI), while the GA lure was obtained from ChemTica International (San Jose, Costa Rica). The BZ and PE lures were in liquid form and were used without any major modifications through either dilution or mixing with solvents. The GA lure dispenser consisted of a heat-sealed polymer membrane.

2.3. Four-Choice Olfactometer Bioassays. A four-choice olfactometer (Analytical Research Systems, Gainesville, FL) was used to determine the behavioral response of adult plum curculio of different physiological states to the above lures. The four-choice olfactometer system was similar to that described by $[38,39]$. Briefly, the apparatus consisted of a central chamber $(30 \times 30 \times 5 \mathrm{~cm})$ with orifices (arms) at the four corners through which purified and humidified air can be drawn in, creating four potential odor fields, and a central orifice where mixing of the airflow from the arms occurred. In the two experiments described below, only two (adjacent to each other) of the four orifices were designated for lure treatments while the other two adjacent orifices were designated for control (i.e., blank dispenser). In other words, only two lure treatments (binary tests) were compared at a given time. Although the device is designed to use push air, we did not use push air in this study because preliminary experiments indicated that plum curculio responded better to the lures under minimal airflow (near still air) conditions, as has been previously reported [20]. This may be related to the tendency of plum curculio to feign death upon the slightest disturbance. The BZ and PE lures were dispensed by transferring aliquots into $0.8 \mathrm{~mL}$ microcentrifuge vials (USA Scientific Inc., Ocala, FL) in which a cotton string $(\sim 2.5 \mathrm{~cm}$ long) was threaded through a hole drilled through the lid of the cap to aid in the release of the lures. The GA lure dispenser consisted of a heat-sealed polymer membrane to protect the pheromone. The membrane was removed before placing the dispenser in the olfactometer arm. The lure treatments were placed in their designated olfactometer arms for $20 \mathrm{~min}$ prior to release of test weevils to ensure the stabilization of the diffusion of the lures.

2.4. Olfactometer Response of Plum Curculio to Commercial Lures. Two separate experiments were conducted to evaluate 
response of plum curculio to the three tested lures. In the first experiment, single lures were evaluated as binary or paired treatments (i.e., $\mathrm{BZ}$ versus $\mathrm{PE}, \mathrm{BZ}$ versus $\mathrm{GA}$, and $\mathrm{PE}$ versus $\mathrm{GA}$ ). In the second experiment, the most attractive single lure determined in the first experiment (i.e., PE) was selected and compared against combined (two component) lure treatments in binary tests (i.e., $\mathrm{PE}$ versus $\mathrm{BZ}+\mathrm{PE}, \mathrm{PE}$ versus $B Z+G A$, and $P E$ versus $P E+G A)$ to determine the type of interaction (i.e., additive, synergistic, neutral, or negative/inhibitory) between any two lures. Weevils of different physiological states such as food deprivation (starved for $24 \mathrm{~h}$ versus fed ad libitum), age (preoviposition adults or 10-14-day olds versus oviposition-postoviposition adults or 20-24-day olds), and mating status (unmated versus mated) were tested in both experiments to determine the effect of the above physiological factors on the response of plum curculio to the lures. We considered $24 \mathrm{hr}$ starvation to be enough to generate "hungry" weevils following $[15,16]$. These resulted in a total of eight physiological treatments per sex. Groups of five females or males of each physiological treatment were released in the olfactometer and replicated six times per sex. Released weevils were given $30 \mathrm{~min}$ to respond by walking into one of the four olfactometer arms. Those that did not make a choice within this period were considered as "nonresponders" and excluded from the test. A weevil was used only once. At the end of the test with each physiological treatment, the olfactometer set-up was rinsed with soap, water, and acetone. The glassware was then heated in an oven to about $200^{\circ} \mathrm{C}$ for $\sim 6 \mathrm{~h}$ before reuse. The position of each lure in the olfactometer was alternated after each replicate (i.e., lures were reassigned to different olfactometer arms) to minimize position effect. All bioassays were carried out under red light in a dark room at $25 \pm 1^{\circ} \mathrm{C}, 55 \pm 10 \%$ RH between 1600 and $2400 \mathrm{~h}$ local time from June 2008 to December 2009. The time of day chosen was based on previous report which showed plum curculio adults to be most active in the field during scotophase [40, 41]. Data from each experiment were first analyzed by using standard least square analysis of variance (ANOVA), a model capable of determining the effects of multiple factors, to test for effects of sex (male versus female), age (preoviposition adults or 10-14-day olds versus oviposition-postoviposition adults or 20-24-days olds), diet (fed versus starved for $24 \mathrm{hr}$ ), mating status (mated versus unmated), and lure treatments on the response of plum curculio. The model also allowed testing for effects of single (one-way), double (two-way), triple (threeway), ternary (four-way), and five-way interactions (a total of 31 possible interactions) (Table 1) among the five factors. Because the model showed no significant effect of age, diet, mating status, or interactions among the majority of the factors on response of plum curculio to the lure treatments (Table 1), data for these physiological treatments were pooled for each sex and analyzed using one-way ANOVA followed by the Tukey-Kramer honestly significant difference (HSD) test to determine significant differences in the response of each sex to the different lure treatments [42].

2.5. Olfactometer Response of Plum Curculio to Synthetic Chemical Components in Commercial Lures. Olfactometer bioassays were conducted to evaluate the response of plum curculio to the key chemical components of the $\mathrm{BZ}$ and $\mathrm{PE}$ lures which are BZ and TCB. The aim was to determine the biologically active chemical components in each lure. The synthetic pure compounds identified in each lure were obtained from Sigma Chemical Co. (St. Louis, MO, USA) and tested against the commercial lures in four-choice olfactometer bioassays using the procedures described above for the lures. One difference was that three odor treatments were compared simultaneously (i.e., multiple treatment comparisons). For this, three of the four arms of the olfactometer were designated for odor treatments, while the remaining arm was designated as hexane control. Two experiments were conducted each comparing three odor treatments versus control consisting of empty microcentrifuge vials. In experiment 1, pure benzaldehyde (BEN) and pure 1,2,4-trichlorobenzene (TCB), the two key chemical components identified in the commercial BZ lure, were compared against BZ lure. The dose of BEN and TCB tested in the olfactometer was similar to the amount of each compound detected in BZ lure by GCMS. Based on the results of the above first experiment we hypothesized that TCB, which is commercially formulated with BZ lure as a stabilizing agent (but not formulated with PE lure), is likely the compound responsible for the relatively lower attractiveness of BZ lure compared to PE lure. To test this hypothesis regarding "repellent" or "dampening" effect of TCB when formulated with the BZ or PE lure, a second experiment was conducted which compared PE lure (found to be highly attractive in the previous lure tests), pure TCB, and mixture of PE and TCB (PE + TCB). If TCB truly has a repellent or inhibitory effect, we would expect the combined $\mathrm{PE}+\mathrm{TCB}$ treatment to be less attractive than PE lure. TCB was tested singly with $\mathrm{PE}$ at a dose similar to that detected in the BZ lure. In the mixed PE + TCB treatment, both compounds were released from separate vials placed in the assigned olfactometer arm. For each experiment, groups of five female or male weevils ( $>20$ days old, mated, and starved for $24 \mathrm{~h}$ ) were released in the olfactometer. The experiment was replicated 12 times per sex. Data for each sex were analyzed using one-way ANOVA followed by the TukeyKramer HSD test to determine significant differences in the response of female or male weevils to the different odor treatments [42].

2.6. Estimation of Release Rates of Commercial Lures and Synthetic Components. The release rates of the commercial lures (BZ and PE) and pure synthetic components identified as released by the lures (BEN/TCB for BZ lure and BEN for $\mathrm{PE}$ lure) were determined gravimetrically in the laboratory using the methods described by [29]. Briefly, $\sim 0.8 \mathrm{~mL}$ of each treatment (i.e., BZlure, PE lure, BEN, or TCB) was transferred into a microcentrifuge vial, which was then weighed on a microbalance (Ohaus Adventurer Analytical Balance; model AR2140, Central Carolina Scale, Sanford, NC). Each vial was then placed in one of the chambers of the four-choice olfactometer. The experiment was conducted at $25 \pm 1^{\circ} \mathrm{C}$, $55 \pm 10 \% \mathrm{RH}$ between 1600 and $2400 \mathrm{~h}$ local time. The weight of each vial was determined again $24 \mathrm{~h}$ later. The experiment was repeated seven times using fresh vials and compounds 
TABLE 1: Standard least squares analyses of variance testing for effects of age, diet, lure type, mating status, and sex and their interactions on response of C. nenuphar to single components of benzaldehyde (BZ), plum essence (PE), and grandisoic acid (GA).

\begin{tabular}{|c|c|c|c|c|c|c|c|c|c|c|c|}
\hline \multirow{2}{*}{ Type of effect } & \multirow{2}{*}{ Source of variation } & \multirow{2}{*}{ d.f. } & \multicolumn{3}{|c|}{$\mathrm{BZ}$ versus $\mathrm{PE}$} & \multicolumn{3}{|c|}{ GA versus $\mathrm{PE}$} & \multicolumn{3}{|c|}{ GA versus $B Z$} \\
\hline & & & MS & $F$ & $P$ & MS & $F$ & $P$ & MS & $F$ & $P$ \\
\hline \multirow{5}{*}{ Single } & Age & 1 & 0.21 & 0.35 & 0.5524 & 0.09 & 0.13 & 0.7158 & 0.00 & 0.00 & 1.0000 \\
\hline & Diet & 1 & 0.07 & 0.11 & 0.7413 & 1.26 & 1.78 & 0.1825 & 0.17 & 0.22 & 0.6360 \\
\hline & Lure type & 3 & 465.03 & 259.93 & $<0.0001$ & 367.65 & 173.52 & $<0.0001$ & 52.30 & 23.47 & $<0.0001$ \\
\hline & Mating status & 1 & 0.02 & 0.04 & 0.8430 & 0.17 & 0.24 & 0.6275 & 0.09 & 0.13 & 0.7226 \\
\hline & Sex & 1 & 0.07 & 0.11 & 0.7413 & 0.01 & 0.01 & 0.9034 & 0.17 & 0.22 & 0.6360 \\
\hline \multirow{11}{*}{ Double } & Age $*$ lure type & 3 & 3.57 & 2.00 & 0.1145 & 3.43 & 1.62 & 0.1852 & 2.60 & 1.17 & 0.3217 \\
\hline & Diet $*$ age & 1 & 0.07 & 0.11 & 0.7413 & 0.04 & 0.06 & 0.8082 & 0.51 & 0.69 & 0.4077 \\
\hline & Diet $*$ age $*$ lure type & 3 & 2.22 & 1.24 & 0.2957 & 1.81 & 0.86 & 0.4645 & 1.76 & 0.79 & 0.5001 \\
\hline & Diet $*$ lure type & 3 & 8.51 & 4.76 & 0.0029 & 2.43 & 1.15 & 0.3308 & 5.98 & 2.68 & 0.0468 \\
\hline & Mating status $*$ age & 1 & 0.59 & 0.98 & 0.3223 & 0.01 & 0.01 & 0.9034 & 0.00 & 0.00 & 1.0000 \\
\hline & Mating status $*$ diet & 1 & 0.07 & 0.11 & 0.7413 & 0.09 & 0.13 & 0.7158 & 0.67 & 0.90 & 0.3441 \\
\hline & Mating status $*$ lure type & 3 & 0.38 & 0.21 & 0.8867 & 2.85 & 1.35 & 0.2591 & 0.72 & 0.32 & 0.8090 \\
\hline & Sex $*$ age & 1 & 0.07 & 0.11 & 0.7413 & 0.04 & 0.06 & 0.8082 & 0.01 & 0.01 & 0.9058 \\
\hline & Sex $*$ diet & 1 & 0.07 & 0.11 & 0.7413 & 0.04 & 0.06 & 0.8082 & 0.09 & 0.13 & 0.7226 \\
\hline & Sex $*$ lure type & 3 & 7.05 & 3.94 & 0.0088 & 5.43 & 2.56 & 0.0549 & 7.35 & 3.30 & 0.0207 \\
\hline & Sex $*$ mating status & 1 & 0.21 & 0.35 & 0.5524 & 0.09 & 0.13 & 0.7158 & 0.67 & 0.90 & 0.3441 \\
\hline \multirow{9}{*}{ Triple } & Mating status $*$ age $*$ lure type & 3 & 2.20 & 1.23 & 0.2999 & 1.68 & 0.79 & 0.4993 & 9.44 & 4.24 & 0.0059 \\
\hline & Mating status $*$ diet $*$ age & 1 & 0.1276 & 0.21 & 0.6440 & 0.04 & 0.06 & 0.8082 & 0.01 & 0.01 & 0.9058 \\
\hline & Mating status $*$ diet $*$ lure type & 3 & 0.76 & 0.42 & 0.7362 & 7.84 & 3.70 & 0.0121 & 2.40 & 1.08 & 0.3597 \\
\hline & Sex $*$ age $*$ lure type & 3 & 2.59 & 1.45 & 0.2287 & 5.98 & 2.82 & 0.0390 & 1.22 & 0.55 & 0.6505 \\
\hline & Sex $*$ diet $*$ age & 1 & 0.07 & 0.11 & 0.7413 & 0.09 & 0.13 & 0.7158 & 0.00 & 0.00 & 1.0000 \\
\hline & Sex $*$ diet $*$ lure type & 3 & 2.38 & 1.33 & 0.2639 & 3.48 & 1.64 & 0.1795 & 6.09 & 2.73 & 0.0437 \\
\hline & Sex $*$ mating status $*$ age & 1 & 0.32 & 0.53 & 0.4678 & 0.04 & 0.06 & 0.8082 & 0.01 & 0.01 & 0.9058 \\
\hline & Sex $*$ mating status $*$ diet & 1 & 0.07 & 0.11 & 0.7413 & 0.00 & 0.00 & 1.0000 & 0.51 & 0.69 & 0.4077 \\
\hline & Sex $*$ mating status $*$ lure type & 3 & 2.07 & 1.16 & 0.3262 & 3.01 & 1.42 & 0.2366 & 3.19 & 1.43 & 0.2338 \\
\hline \multirow{5}{*}{ Ternary } & Mating status $*$ diet $*$ age $*$ lure type & 3 & 1.07031 & 0.60 & 0.6166 & 2.56 & 1.21 & 0.3063 & 6.59 & 2.96 & 0.0325 \\
\hline & Sex $*$ diet $*$ age $*$ lure type & 3 & 2.09 & 1.17 & 0.3217 & 3.18 & 1.50 & 0.2146 & 0.15 & 0.07 & 0.9781 \\
\hline & Sex $*$ mating status $*$ age $*$ lure type & 3 & 0.51 & 0.28 & 0.8371 & 0.98 & 0.46 & 0.7089 & 0.14 & 0.06 & 0.9804 \\
\hline & Sex $*$ mating status $*$ diet $*$ age & 1 & 0.00 & 0.00 & 0.9474 & 0.01 & 0.01 & 0.9034 & 0.17 & 0.22 & 0.6360 \\
\hline & Sex $*$ mating status $*$ diet $*$ lure type & 3 & 4.47 & 2.50 & 0.0598 & 2.44 & 1.15 & 0.3289 & 2.18 & 0.98 & 0.4037 \\
\hline Five-way & Sex $*$ mating status $*$ diet $*$ age $*$ lure type & 3 & 0.90 & 0.51 & 0.6790 & 2.18 & 1.03 & 0.3806 & 3.06 & 1.37 & 0.2505 \\
\hline
\end{tabular}

Numbers in bold indicate effects which showed significant differences (ANOVA, Tukey-Kramer HSD, $P<0.05$ ).

each time. The release rate of GA lure was also determined in a parallel study using the same procedures. The mean release rates ( $\mathrm{mg} /$ day) were calculated for each lure and the synthetic form of their components. A one way ANOVA was performed followed by the Tukey-Kramer HSD test to determine significant differences in the release rates of the different lures and synthetic compounds [42].

\section{Results}

3.1. Olfactometer Response of Plum Curculio to Commercial Lures. Standard least squares analyses of the data from the first experiment (BZ versus PE binary test) revealed no significant effect of sex $(F=0.11$, d.f. $=1$, and $P=0.7413)$, age $(F=0.35$, d.f. $=1$, and $P=0.5524)$, diet $(F=0.11$, d.f. $=1$, and $P=0.7413)$, or mating status $(F=0.04$, d.f. $=1$, and $P=0.8430$ ) on plum curculio response (Table 1 ). However, the effect of lure was highly significant $(F=259.93$, d.f. $=3$, and $P<0.0001$ ) (Table 1 ). The only two significant interactions recorded were sex $\times$ lure $(F=3.94$, d.f. $=3$, and $P=0.0088)$ and diet $\times$ lure $(F=4.76$, d.f. $=3$, and $P<$ 0.0029) (Table 1). Similar results were obtained for the other binary treatment comparisons of single lures (i.e., BZ versus $G A$ and $P E$ versus $G A$ ) or mixed lures (i.e., $P E$ versus $B Z+P E$, $P E$ versus $B Z+G A$, and $P E$ versus $P E+G A)$. Based on these results which indicated that the physiological conditions of adult plum curculio have very little effect on their response to the lures, data obtained for weevils of different physiological states (i.e., age, diet, and mating) were pooled by sex and analyzed using one-way ANOVA to compare response of each sex to different lure treatments.

Analysis of the pooled data showed that when BZ and $\mathrm{PE}$ were compared as binary odor treatments, plum curculio 


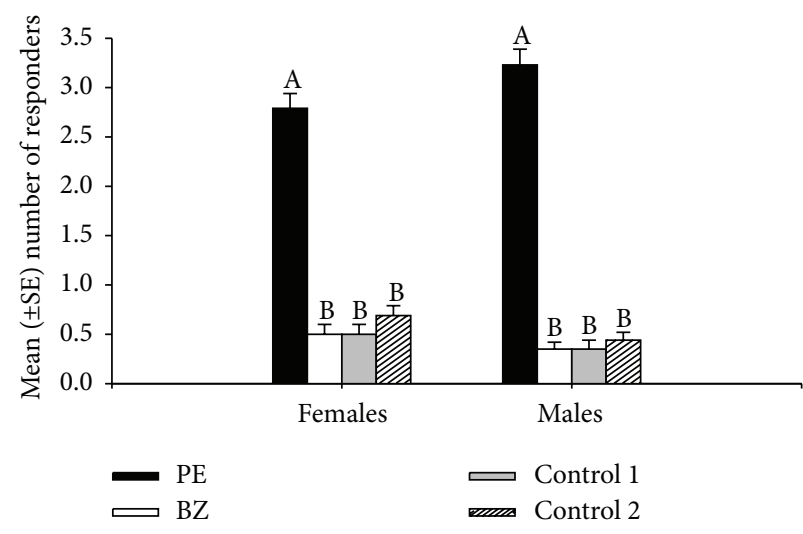

(a)

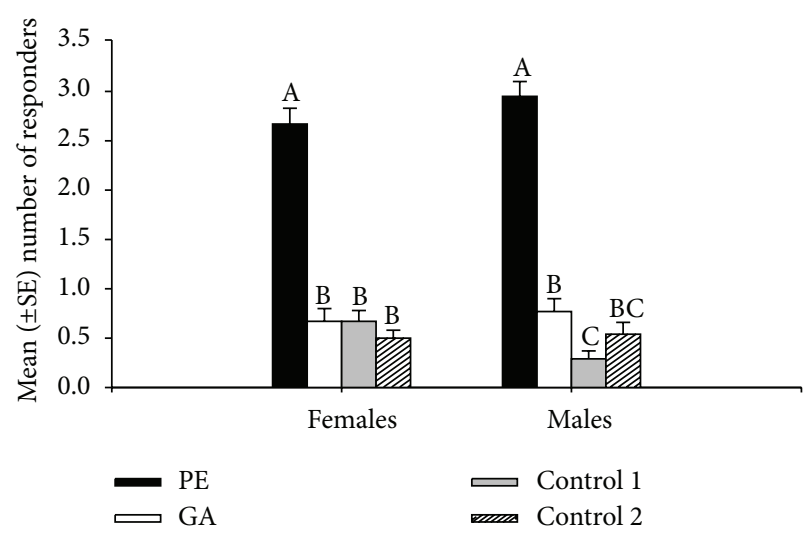

(b)

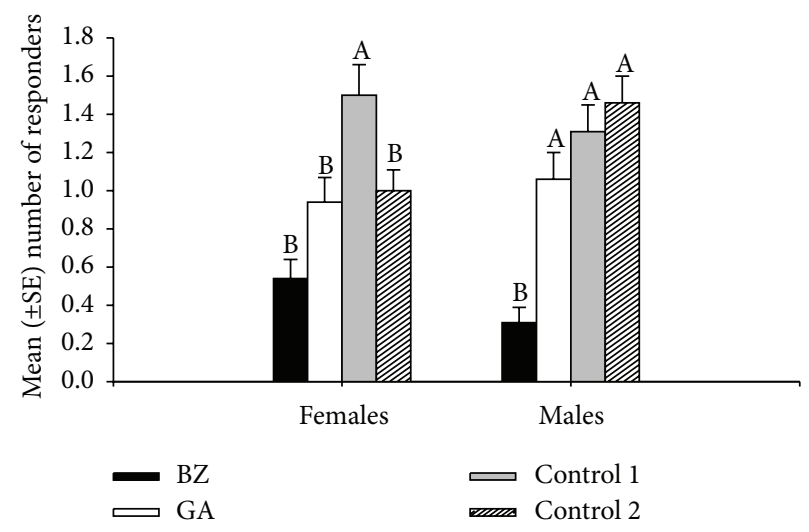

(c)

FIGURE 1: Response of plum curculio to commercial lures of benzaldehyde (BZ), plum essence (PE), and grandisoic acid (GA) in four-choice olfactometer bioassays. In each test, two lure treatments (binary test) and two controls were compared: (a) BZ versus PE; (b) PE versus GA; and (c) BZ versus GA. In this figure and Figure 2, Control $1=$ air and Control $2=$ empty microcentrifuge vial. Groups of five weevils of either sex were released per test in the olfactometer and replicated six times. Means for each sex having no letter in common are significantly different (ANOVA, Tukey-Kramer HSD, $P<0.05$ ).

females $(F=92.29$, d.f. $=3$, and $P<0.0001)$ and males $(F=175.6$, d.f. $=3$, and $P<0.0001)$ were significantly more attracted to PE than to BZ or the controls (Figure 1(a)). Similarly, the results of the binary comparison of GA versus $\mathrm{PE}$ showed significantly greater attraction of females $(F=$ 69.06, d.f. $=3$, and $P<0.0001)$ and males $(F=104.4$, d.f. $=3$, and $P<0.0001$ ) to PE than to GA or the controls (Figure 1(b)). The results of the binary comparison of BZ versus GA showed greater response of females to one of the controls than to $\mathrm{BZ}$ or GA $(F=9.8$, d.f. $=3$, and $P<0.0001$ ), and no differences were recorded between $\mathrm{BZ}$ and GA (Figure 1(c)). Similarly, significantly fewer males responded to BZ compared to GA or the controls $(F=16.4$, d.f. $=3$, and $P<0.0001$ ) (Figure 1(c)). Together, these results indicate the nonattractiveness of BZ and GA lures in our olfactometer bioassays.

The results of the second binary experiments in which $\mathrm{PE}$ was compared against a combined lure treatment (i.e., $\mathrm{BZ}+\mathrm{PE}, \mathrm{BZ}+\mathrm{GA}$, or $\mathrm{PE}+\mathrm{GA}$ ) confirmed the superior attractiveness of the PE lure (Figure 2). In the binary comparison of $\mathrm{PE}$ versus $\mathrm{BZ}+\mathrm{PE}$, both the females $(F=89.5$, d.f. $=3$, and $P<0.0001)$ and males $(F=42.7$, d.f. $=3$, and $P<0.0001)$ showed greater response to $\mathrm{PE}$ than to $\mathrm{BZ}+$ $\mathrm{PE}$ or the controls (Figure 2(a)). Similarly, females $(F=65.9$, d.f. $=3$, and $P<0.0001)$ and males $(F=76.4$, d.f. $=3$, and $P<0.0001)$ were more attracted to $\mathrm{PE}$ than to $\mathrm{BZ}+\mathrm{GA}$ or the controls (Figure 2(b)). Females $(F=34.27$, d.f. $=3$, and $P<0.0001)$ and males $(F=45.56$, d.f. $=3$, and $P<0.0001)$ also showed greater attraction to PE than to PE + GA or the controls (Figure 2(c)). Similar results were also obtained when $\mathrm{PE}$ was compared against a treatment consisting of the three lures (i.e., BZ + PE + GA; data not presented). In addition to confirming the superior attractiveness of $\mathrm{PE}$, these results also showed the nonattractiveness of BZ not only as a single lure but also when combined with PE.

\subsection{Olfactometer Response of Plum Curculio to Chemical} Components in Commercial Lures. Four-choice olfactometer tests were conducted to evaluate response of plum curculio to multiple treatments comprising the lures and their key chemical components (i.e., 3 odor treatments and 1 control). In experiment 1 , the following four treatments were compared: BZ lure, pure synthetic BEN, pure synthetic TCB, and control. The results showed that females $(F=9.64$, d.f. $=3$, and 


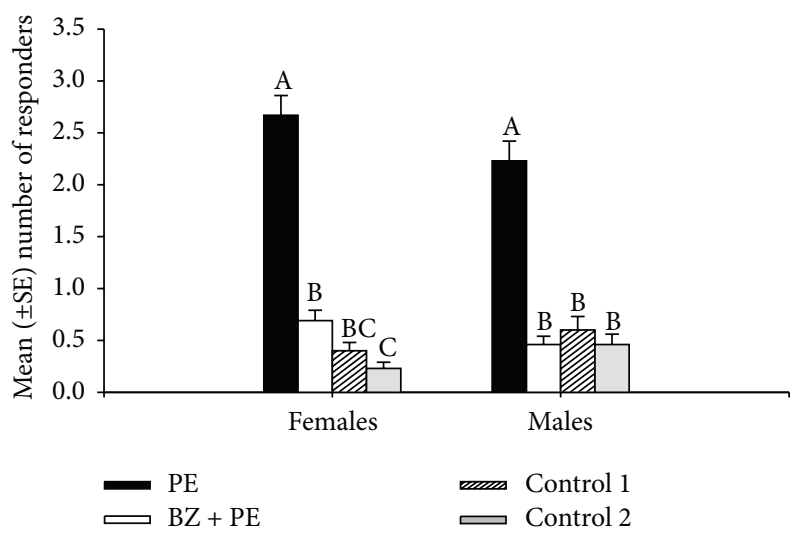

(a)

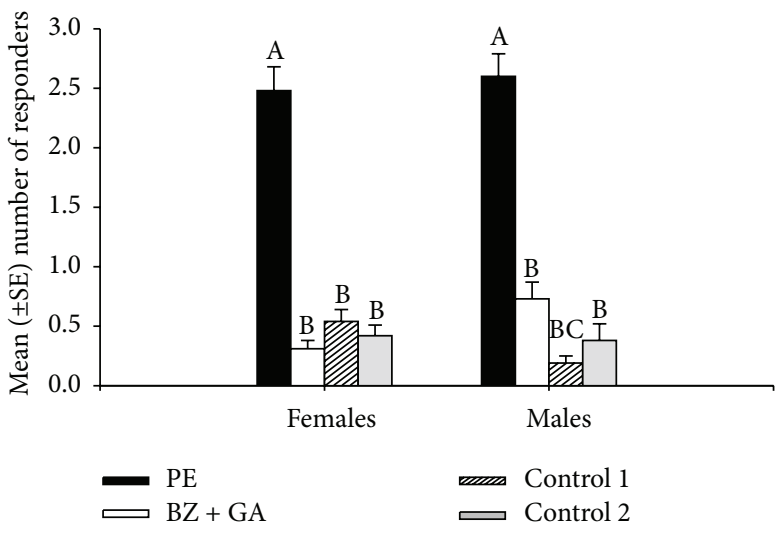

(b)

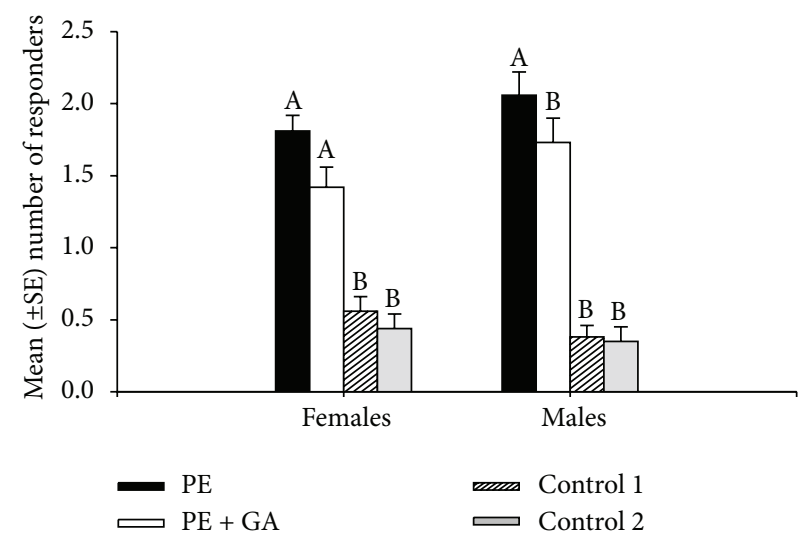

(c)

FIGURE 2: Response of plum curculio to combinations of commercial lures of benzaldehyde (BZ), plum essence (PE), and grandisoic acid (GA) in four-choice olfactometer bioassays. In each binary test, PE was compared against any two combinations of the three lures: (a) PE versus $\mathrm{BZ}+\mathrm{PE}$, (b) PE versus BZ + GA, and (c) PE versus PE + GA. Groups of five weevils of either sex were released per test in the olfactometer and replicated six times. Means for each sex having no letter in common are significantly different (ANOVA, Tukey-Kramer HSD, $P<0.05$ ).

$P<0.0001)$ and males $(F=6.87$, d.f. $=3$, and $P<$ 0.0007 ) were significantly more responsive to the control than to BZ lure or TCB (Table 2). Both sexes also showed slightly lower response to $\mathrm{BEN}$ than to the control. The results of experiment 2 in which PE was compared against TCB and PE + TCB showed that females were significantly more attracted to PE than to TCB or the control $(F=17.27$, d.f. $=3$, and $P<$ 0.0001). Also, females were numerically more attracted to PE than to PE + TCB (Table 3). Similarly, males were significantly more attracted to $\mathrm{PE}$ than to the remaining treatments $(F=$ 12.50 , d.f. $=3$, and $P<0.0001$ ) (Table 2). These results again confirmed the attractiveness of the PE lure and the inhibitory effect of TCB when mixed with PE.

3.3. Estimation of Release Rates of Commercial Lures and Synthetic Components. Significant differences in release rates were recorded among the lures and compounds (i.e., BEN, BZ, PE, and TCB $)(F=60.66$, d.f. $=3$, and $P<0.0001)$. The gravimetric release rate of $\mathrm{PE}$ was much higher than the release rates of the other treatments (Table 3).

\section{Discussion}

The results of this laboratory study confirmed the attractiveness of the commercial plum essence lure (PE) (a synthetic mixture of plant essence) to plum curculio. Of the tested lures and synthetic components, PE was by far the most attractive to both sexes. This finding is in agreement with previous reports of $\mathrm{PE}$ as an attractant for plum curculio in the field $[9,23,24]$. The relatively greater attractiveness of PE lure may be due to its higher release rates, as determined in the release rate experiment. Our results, however, showed that the commercial benzaldehyde (BZ) lure was not attractive to plum curculio in olfactometer bioassays. This somewhat surprising finding is in contrast to the results of field studies which demonstrated attraction of plum curculio to traps baited with benzaldehyde [17]. In fact, BZ lure is commonly regarded as the most attractive lure for plum curculio when combined with GA and is widely used for monitoring the pest in the field $[17,26,28,43]$. The third commercial lure tested, grandisoic acid (GA), which is the male-produced aggregation pheromone of plum curculio [25] was also not 
TABLE 2: Response of C. nenuphar to the tested commercial lures and synthetic pure compounds in four-choice olfactometer bioassays.

\begin{tabular}{|c|c|c|c|}
\hline \multirow{2}{*}{ Experiment } & \multirow{2}{*}{ Compounds/lure treatments } & \multicolumn{2}{|c|}{ Mean $( \pm \mathrm{SE})$ number of responders } \\
\hline & & Female & Male \\
\hline \multirow{6}{*}{1} & $\mathrm{BZ}$ & $0.25 \pm 0.10 c$ & $0.50 \pm 0.15 b$ \\
\hline & BEN & $1.17 \pm 0.24 \mathrm{ab}$ & $0.92 \pm 0.19 \mathrm{ab}$ \\
\hline & TCB & $0.58 \pm 0.15 \mathrm{bc}$ & $0.58 \pm 0.15 b$ \\
\hline & Control & $1.83 \pm 0.32 \mathrm{a}$ & $1.50 \pm 0.19 \mathrm{a}$ \\
\hline & & $F_{3,44}=9.64$ & $F_{3,44}=6.87$ \\
\hline & & $P<0.0001$ & $P<0.0007$ \\
\hline \multirow{6}{*}{2} & $\mathrm{PE}$ & $2.08 \pm 0.26 \mathrm{a}$ & $2.42 \pm 0.38 \mathrm{a}$ \\
\hline & ТCB & $0.17 \pm 0.11 \mathrm{~b}$ & $0.33 \pm 0.19 b$ \\
\hline & $\mathrm{PE}+\mathrm{TCB}$ & $1.42 \pm 0.19 \mathrm{a}$ & $0.92 \pm 0.19 \mathrm{a}$ \\
\hline & Control & $0.58 \pm 0.19 b$ & $0.92 \pm 0.19 \mathrm{~b}$ \\
\hline & & $F_{3,44}=17.27$ & $F_{3,44}=12.50$ \\
\hline & & $P<0.0001$ & $P<0.0001$ \\
\hline
\end{tabular}

BZ: commercial benzaldehyde lure; BEN: pure synthetic benzaldehyde; TCB: pure synthetic 1,2,4-trichlorobenzene; PE: commercial plum essence lure. For each experiment, groups of 5 weevils of either sex were released per test in the olfactometer and replicated 12 times. For each experiment and sex, means having no letter in common are significantly different (ANOVA, Tukey-Kramer HSD, $P<0.05$ ).

TABLE 3: Release rates of the tested commercial lures and synthetic pure compounds under laboratory conditions.

\begin{tabular}{lc}
\hline & Mean $( \pm$ SE) release rates mg per hour \\
\hline BZ & $0.36 \pm 0.05 \mathrm{~b}$ \\
PE & $1.51 \pm 0.13 \mathrm{a}$ \\
$\mathrm{BEN}$ & $0.29 \pm 0.09 \mathrm{~b}$ \\
$\mathrm{TCB}$ & $0.08 \pm 0.01 \mathrm{~b}$ \\
$\mathrm{GA}^{*}$ & ca. 0.041 \\
\hline
\end{tabular}

BZ: commercial benzaldehyde lure; PE: commercial plum essence lure; BEN: pure synthetic benzaldehyde; TCB: pure synthetic 1,2,4-trichlorobenzene; GA: grandisoic acid. Means having no letter in common are significantly different (ANOVA, Tukey-Kramer HSD, $P<0.05 ; n=5$ ). ${ }^{*}$ Release rate was calculated based on manufacturer's recommendation.

attractive to both sexes when tested either as single lure or in combination with other lures. The results of the experiments in which combined lures were tested further confirmed the superior attractiveness of PE lure, which was more attractive than any combinations of the three lures. Combining BZ or GA lure with PE lure resulted in reduced attractiveness of PE lure. The data actually suggest a repellent or inhibitory effect of BZ when combined with $\mathrm{PE}$ and a neutral effect of combining GA with PE. These results are again contrary to some field studies which reported either a synergistic effect of combining BZ or GA lures [26] or an additive interaction between $\mathrm{BZ}$ and $\mathrm{PE}$ and between $\mathrm{BZ}$ and GA [9]. The combined BZ + GA lure is presently the most widely used attractant for monitoring plum curculio in orchards [22, 26, 28-30]. Also, a recent field study by our group showed that the combined $\mathrm{BZ}+\mathrm{PE}$ was the most effective lure for monitoring plum curculio in Alabama peaches [9]. However, both combined lures (BZ + GA and BZ + PE lures) were not as attractive as the single PE lure in the present study. The difference between the results of this laboratory study and the above field reports may be related to differences between experimental conditions and other factors such as the release rates of the lures. Chemical compounds such as the lures tested in this study, which depend on prevailing environmental conditions to be released in the right concentration, are likely to vary in their performance in fluctuating field conditions compared to the more stable laboratory environment. Intriguingly, the results of the GCMS analyses of the lures showed that benzaldehyde (BEN) was the major component released from both $\mathrm{BZ}$ and $\mathrm{PE}$ lures (Akotsen-Mensah et al., unpublished). Why then is PE lure more attractive than BZ lure? The answer to this question is possibly related to the presence of 1,2,4-trichlorobenzene (TCB) in BZ lure. TCB is formulated with BZ lure as a stabilizing agent and was the only additional component released from BZ lure. TCB, however, was not detected in PE lure. This led us to hypothesize that the reduced attractiveness (or inhibitory effect) of BZ lure was due to TCB. We tested this hypothesis by comparing attraction of plum curculio to PE, TCB, and PE + TCB. The results indicated reduced attraction of plum curculio to $\mathrm{PE}+\mathrm{TCB}$ compared to $\mathrm{PE}$ alone. However, it was unclear if TCB actually played a role in the observed nonattractiveness of $\mathrm{BZ}$ lure since the weevils were also not attracted to pure synthetic BEN. There is currently no evidence which suggests that TCB is a component of the general volatiles complex released by any of the host plants of plum curculio. Hence, we can only speculate that plum curculio is not likely to have evolved the ability to respond to TCB. However, the data which showed a threefold reduction in the response of both sexes to TCB compared to the control may suggest the possibility of an inhibitory effect of TCB. The reduced attractiveness of the combined $\mathrm{PE}+\mathrm{TCB}$ treatment relative to $\mathrm{PE}$ further supports this possibility. Although BEN has been shown to degrade rapidly to benzoic acid and trans-stilbene in the laboratory [22], we did not detect these compounds in our analyses when BZ was exposed in the laboratory for up to 48 hours. Therefore, the nonattractiveness of BZ lure and BEN could not be attributed to degradation to benzoic acid 
and other compounds. Our preliminary result using GCMS analyses which showed that BEN was detected in greater amounts in BZ lure than in PE lure are not as relevant as the release rate results which showed that $\mathrm{PE}$ lure was released at a higher rate ( 4-fold) than BZ lure (Akotsen-Mensah, unpublished). In general, the data showed no significant effect of physiological factors (i.e., age, diet, and mating) or sexual differences on the response of plum curculio to the tested lures. These results led us to reject most of our hypotheses and were somewhat surprising, in particular the null effect of diet on response. We had expected that plum curculio, which uses the same resources (fruit) for food and oviposition, will show greater response to fruit-based odor when starved than when fed. The results are in contrast to those reported by [15], which showed that starved weevils responded more than fed weevils to hexane extract of wild plum. However, it should be noted that the study by [15] used overwintering adults whose physiological conditions were largely unknown (with the exception of diet), whereas the weevils used in the present study were from a laboratory source and with known physiological conditions. Previous studies on the effect of physiological factors on response of other weevil species to odor have produced different results. While some studies have reported significant effect of some physiological factors on beetle response to host odor (e.g., [31-34, 44]), others have reported no effect [45]. In conclusion, the results of this laboratory study demonstrated significant attraction of plum curculio to PE lure. Contrary to field reports, GA lure was not attractive, while BZ lure was inhibitory. The difference between our results and previous field reports may be due to several factors. The inhibitory effects of BZ lure may be due to the presence of TCB. Aside from this, it is plausible that the weevils reared in the laboratory are different from those that occur naturally in the field in their response to odor. In addition, the northern strain of plum curculio tested in most of the field studies and the southern multivoltine strain tested in the present study may differ in their behavioral response to odor. Future studies are necessary to further determine the basis for the inhibitory effect of BZ lure recorded in this study.

\section{Conflict of Interests}

The authors declare that there is no conflict of interests regarding the publication of this paper.

\section{Acknowledgments}

The authors would like to thank Arthur Appel and Robert Boozer (Auburn University) and Louis Jackai (North Carolina A and T State University) for helping to review an earlier version of this paper. The authors also thank Michelle L. Thomas of the University of Georgia, Byron, for assisting with establishment of the plum curculio culture. Funding for this study was provided through grants by the U.S. Environmental Protection Agency (Region 4), Strategic Agricultural Initiative grants program (EPA Grant no. X896450006-0), and Alabama Agricultural Experiment Station grants program to Henry Y. Fadamiro. The topic of this paper was taken from the $\mathrm{PhD}$ thesis of the first author which can be found at the following link: https://etd.auburn .edu/xmlui/bitstream/handle/10415/2300/PhD\%20Dissertation\%208-3-2010.pdf?sequence $=2 \&$ ts $=1444219595450$.

\section{References}

[1] P. J. Chapman, "The plum curculio as an apple pest," New York State Agricultural Experimental Station Bulletin, vol. 684, 75 pages, 1938.

[2] C. S. Beckwith, Insects Attacking Blueberry Fruit, New Jersey Agricultural Experimental Station Circular, New Jersey Agricultural Experiment Station, New Brunswick, NJ, USA, 1943.

[3] C. D. Mampe and H. H. Neunzig, "The biology, parasitism, and population sampling of the plum curculio on blueberry in North Carolina," Journal of Economic Entomology, vol. 60, no. 3, pp. 807-812, 1967.

[4] G. Racette, G. Chouinard, C. Vincent, and S. B. Hill, "Ecology and management of plum curculio in apple orchards," Phytoprotection, vol. 73, pp. 85-100, 1992.

[5] D. L. Horton and H. C. Ellis, "Plum curculio," in Peach Production Handbook, S. C. Myers, Ed., pp. 169-170, Cooperative Extension Service, University of Georgia, Athens, Greece, 1989.

[6] D. L. Horton, "Southeastern peach insect pest managementits evolution and implementation," Tech. Rep., Cooperative Extension Service, University of Georgia, Athens, Ga, USA, 1998.

[7] D. T. Johnson, P. G. Mulder Jr., B. D. McCraw et al., "Trapping plum curculio Conotrachelus nenuphar (Herbst) (Coleoptera: Curculionidae) in the southern United States," Environmental Entomology, vol. 31, no. 6, pp. 1259-1267, 2002.

[8] Z. Lan, H. Scherm, and D. L. Horton, "Temperature-dependent development and prediction of emergence of the summer generation of plum curculio (Coleoptera: Curculionidae) in the southeastern United States," Environmental Entomology, vol. 33, no. 2, pp. 174-181, 2004.

[9] C. Akotsen-Mensah, R. Boozer, and H. Y. Fadamiro, "Field evaluation of traps and lures for monitoring plum curculio, Conotrachelus nenuphar (Coleoptera: Curculionidae) in Alabama peaches," Journal of Economic Entomology, vol. 103, no. 3, pp. 744-753, 2010.

[10] O. I. Snapp, "Life history and habits of the plum curculio in the Georgia peach belt," US Department of Agriculture Technical Bulletin, vol. 188, pp. 1-90, 1930.

[11] O. I. Snapp, "Further studies of the plum curculio in the Georgia peach belt," Journal of Economic Entomology, vol. 33, no. 3, pp. 453-456, 1940.

[12] G. Lafleur, S. B. Hill, and C. Vincent, "Fall migration, hibernation site selection, and associated winter mortality of plum curculio (Coleoptera: Curculionidae) in a Quebec apple orchard," Journal of Economic Entomology, vol. 80, no. 6, pp. 1152-1172, 1987.

[13] S. L. Butkewich and R. J. Prokopy, "The effect of short-range host odor stimuli on host fruit finding and feeding behavior of plum curculio adults (Coleoptera: Curculionidae)," Journal of Chemical Ecology, vol. 19, no. 4, pp. 825-835, 1993.

[14] S. L. Butkewich and R. J. Prokopy, "Attraction of adult plum curculios to host-tree odor and visual stimuli in the field," Journal of Entomological Science, vol. 32, no. 1, pp. 1-6, 1997.

[15] R. J. Prokopy, S. S. Cooley, and P. L. Phelan, "Bioassay approaches to assessing behavioral responses of plum curculio 
adults (Coleoptera: Curculionidae) to host fruit odor," Journal of Chemical Ecology, vol. 21, no. 8, pp. 1073-1084, 1995.

[16] T. C. Leskey and R. J. Prokopy, "Sources of apple odor attractive to adult plum curculios (Coleoptera: Curculionidae)," Journal of Chemical Ecology, vol. 26, no. 3, pp. 639-653, 2000.

[17] T. C. Leskey, R. J. Prokopy, S. E. Wright, P. L. Phelan, and L. W. Haynes, "Evaluation of individual components of plum odor as potential attractants for adult plum curculios," Journal of Chemical Ecology, vol. 27, no. 1, pp. 1-17, 2001.

[18] R. J. Prokopy, B. W. Chandler, S. A. Dynok, and J. C. Piñero, "Odor-baited trap trees: a new approach to monitoring plum curculio (Coleoptera: Curculionidae)," Journal of Economic Entomology, vol. 96, no. 3, pp. 826-834, 2003.

[19] R. J. Prokopy, I. Jácome, E. Gray, G. Trujillo, M. Ricci, and J. C. Piñero, "Using odor-baited trap trees as sentinels to monitor plum curculio (Coleoptera: Curculionidae) in apple orchards," Journal of Economic Entomology, vol. 97, no. 2, pp. 511-517, 2004.

[20] T. C. Leskey and R. J. Prokopy, "Adult plum curculio (Coleoptera: Curculionidae) attraction to fruit and conspecific odors," Annals of the Entomological Society of America, vol. 94, no. 2, pp. 275-288, 2001.

[21] R. J. Prokopy, P. L. Phelan, S. E. Wright, A. J. Minalga, R. Barger, and T. C. Leskey, "Compounds from host fruit odor attractive to plum curculio adults (Coleoptera: Curculionidae)," Journal of Entomological Science, vol. 36, pp. 122-134, 2001.

[22] T. C. Leskey, A. Zhang, and M. Herzog, "Nonfruiting host tree volatile blends: novel attractants for the plum curculio (Coleoptera: Curculionidae)," Environmental Entomology, vol. 34, no. 4, pp. 785-793, 2005.

[23] A. Coombs, Trap designs and attractants for monitoring plum curculio, Conotrachelus nenuphar (Herbst.) [M.S. thesis], Michigan State University, East Lansing, Mich, USA, 2001.

[24] M. Whalon, D. Nortman, J. Wise, L. Gut, and D. Epstein, "Plum curculio management and spray timing," Michigan State University Fruit CAT Newsletter, vol. 21, pp. 1-3, 2006.

[25] F. J. Eller and R. J. Bartelt, "Grandisoic acid, a male-produced aggregation pheromone from the plum curculio, Conotrachelus nenuphar," Journal of Natural Products, vol. 59, no. 4, pp. 451$453,1996$.

[26] J. C. Piñero and R. J. Prokopy, "Field evaluation of plant odor and pheromonal combinations for attracting plum curculios," Journal of Chemical Ecology, vol. 29, no. 12, pp. 2735-2748, 2003.

[27] J. C. Piñero and R. J. Prokopy, "Immigrants or recolonizers? Studying plum curculio movement using odor-baited traps," Fruit Notes, vol. 69, pp. 9-13, 2005.

[28] J. C. Piñero, S. E. Wright, and R. J. Prokopy, "Response of plum curculio (Coleoptera: Curculionidae) to odor-baited traps near woods," Journal of Economic Entomology, vol. 94, no. 6, pp. 1386-1397, 2001.

[29] T. C. Leskey and S. E. Wright, "Influence of host tree proximity on adult plum curculio (Coleoptera: Curculionidae) responses to monitoring traps," Environmental Entomology, vol. 33, no. 2, pp. 389-396, 2004.

[30] J. C. Piñero and R. J. Prokopy, “Temporal dynamics of plum curculio, Conotrachelus nenuphar (Herbst.) (Coleoptera: Curculionidae), immigration into an apple orchard in Massachusetts," Environmental Entomology, vol. 35, no. 2, pp. 413422, 2006.

[31] C. A. Walgenbach, J. K. Phillips, D. L. Faustini, and W. E. Burkholder, "Male-produced aggregation pheromone of the maize weevil, Sitophilus zeamais, and interspecific attraction between three Sitophilus species," Journal of Chemical Ecology, vol. 9, no. 7, pp. 831-841, 1983.

[32] L. E. M. Vet and M. Dicke, "Ecology of infochemical use by natural enemies in a tritrophic context," Annual Review of Entomology, vol. 37, pp. 141-172, 1992.

[33] P. J. Landolt and T. W. Phillips, "Host plant influences on sex pheromone behavior of phytophagous insects," Annual Review of Entomology, vol. 42, pp. 371-391, 1997.

[34] A. M. Fraser, W. L. Mechaber, and J. G. Hildebrand, "Electroantennographic and behavioral responses of the sphinx moth Manduca sexta to host plant headspace volatiles," Journal of Chemical Ecology, vol. 29, no. 8, pp. 1813-1833, 2003.

[35] E. H. Smith, "A method for rearing the plum curculio under laboratory conditions," Journal of Economic Entomology, vol. 50, no. 2, pp. 187-190, 1957.

[36] A. A. Amis and J. W. Snow, "Conotrachelus nenuphar," in Handbook of Insect Rearing, P. Singh and R. F. Moore, Eds., vol. 1, pp. 227-235, Elsevier, New York, NY, USA, 1985.

[37] J. R. Thomson, "Sex differentiation of adults of Conotrachelus nenuphar," Journal of Economic Entomology, vol. 25, no. 4, pp. 807-810, 1932.

[38] J. Pettersson, "Studies on Rhopalosiphum padi (L.) I. Laboratory studies of olfactometric responses to the winter host Prunus padus (L.)," Lantbrukshögskolans Annaler, vol. 36, pp. 381-399, 1970.

[39] T. Kalule and D. J. Wright, "The influence of cultivar and cultivar-aphid odours on the olfactory response of the parasitoid Aphidius colemani," Journal of Applied Entomology, vol. 128, no. 2, pp. 120-125, 2004.

[40] G. Racette, S. B. Hill, and C. Vincent, "Actographs for recording daily activity of plum curculio (Coleopera: Curculionidae)," Journal of Economic Entomology, vol. 83, no. 6, pp. 2385-2392, 1990.

[41] S. Lamothe, G. Chouinard, and C. Vincent, "Abiotic factors and trap design modulate the performance of traps used to monitor the plum curculio," Journal of Economic Entomology, vol. 101, no. 6, pp. 1838-1846, 2008.

[42] SAS Institute, JMP 7.0.1, SAS Institute, Cary, NC, USA, 2007.

[43] T. C. Leskey, J. C. Piñero, and R. J. Prokopy, "Odor-baited trap trees: a novel management tool for plum curculio (Coleoptera: Curculionidae)," Journal of Economic Entomology, vol. 101, no. 4, pp. 1302-1309, 2008.

[44] K. M. Addesso and H. J. McAuslane, "Pepper weevil attraction to volatiles from host and nonhost plants," Environmental Entomology, vol. 38, no. 1, pp. 216-224, 2009.

[45] C. A. Walgenbach and W. E. Burkholder, "Factors affecting the response of the maize weevil, Sitophilus zeamais (Coleoptera: Curculionidae), to its aggregation pheromone," Environmental Entomology, vol. 15, no. 3, pp. 733-738, 1986. 

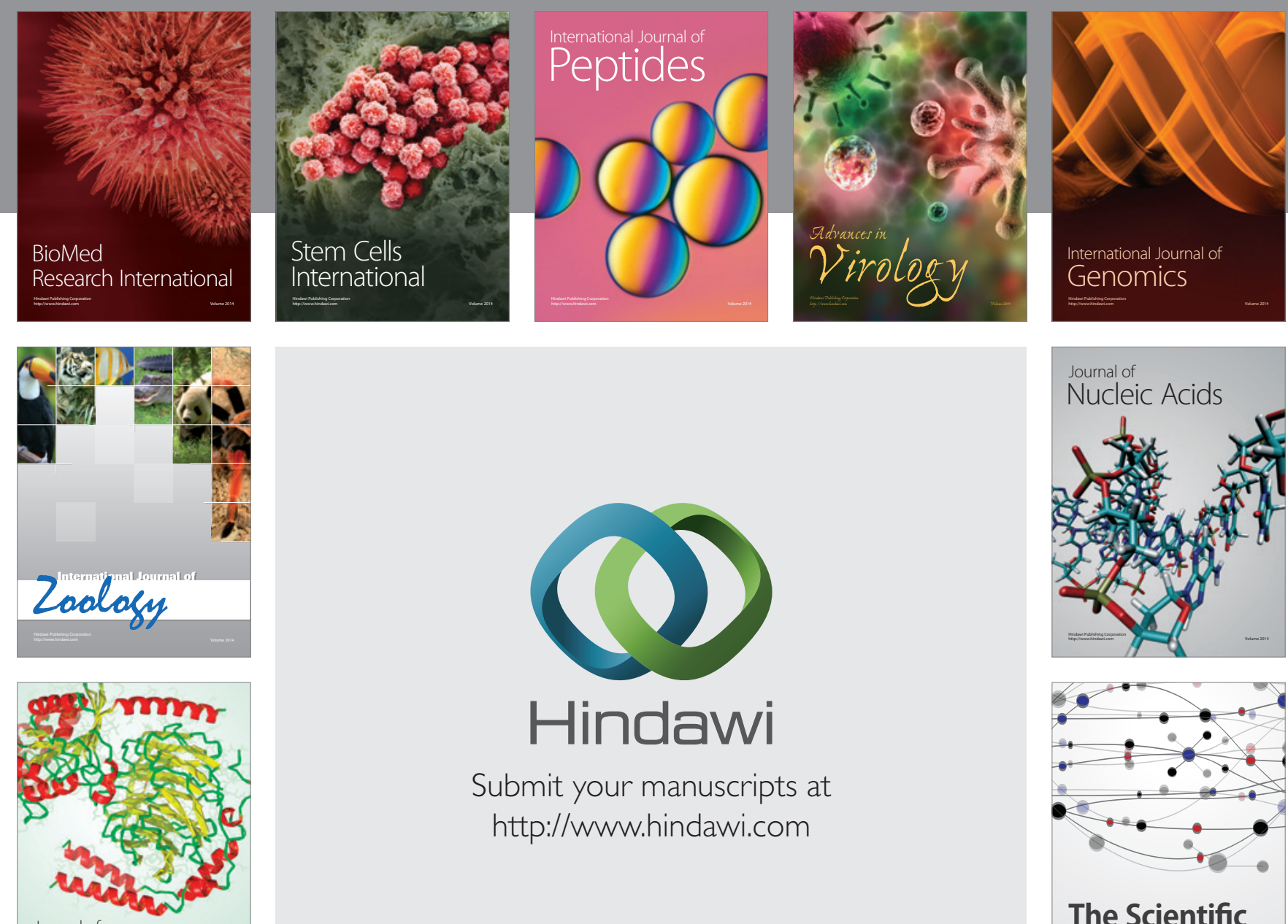

Submit your manuscripts at

http://www.hindawi.com

Journal of
Signal Transduction
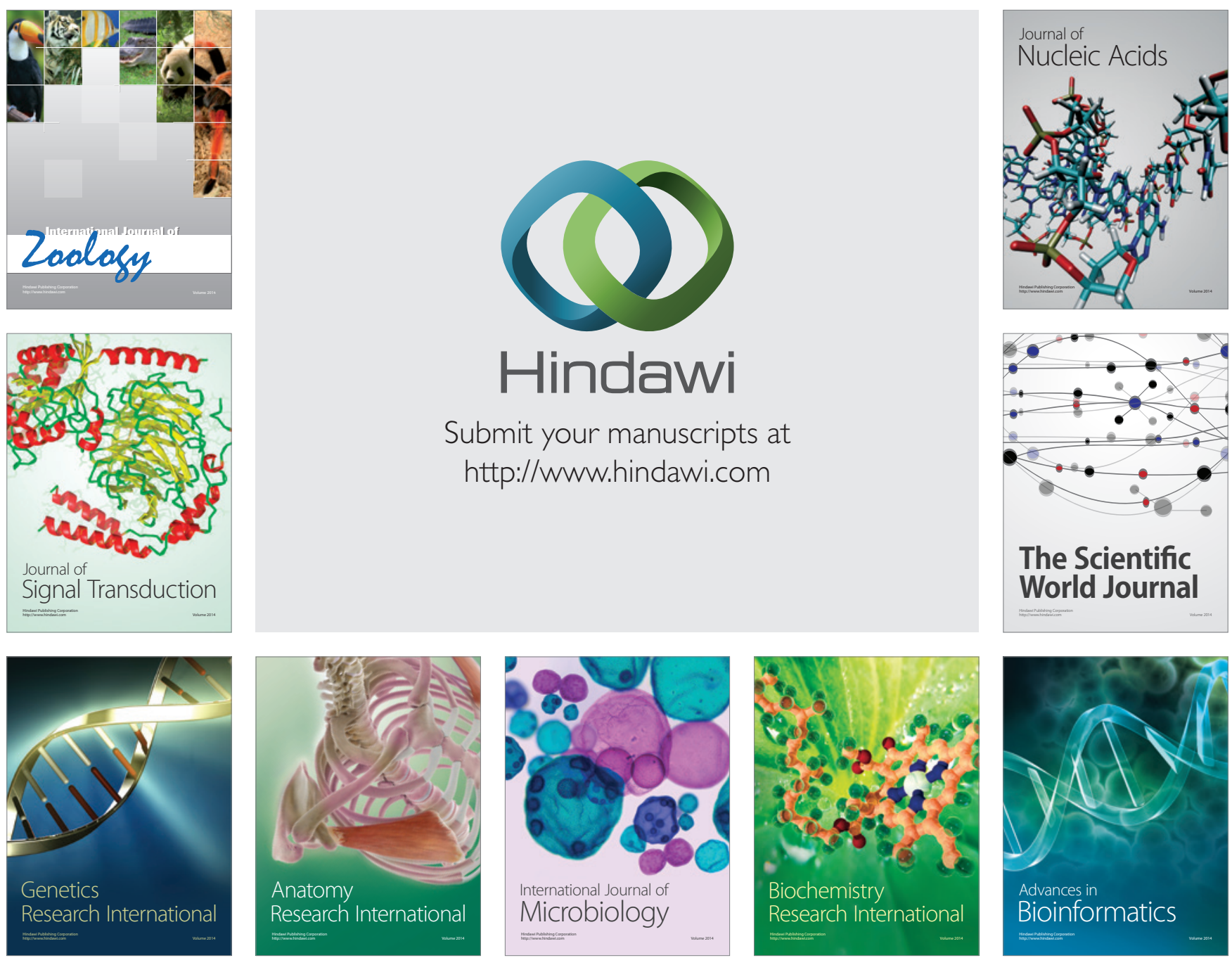

The Scientific World Journal
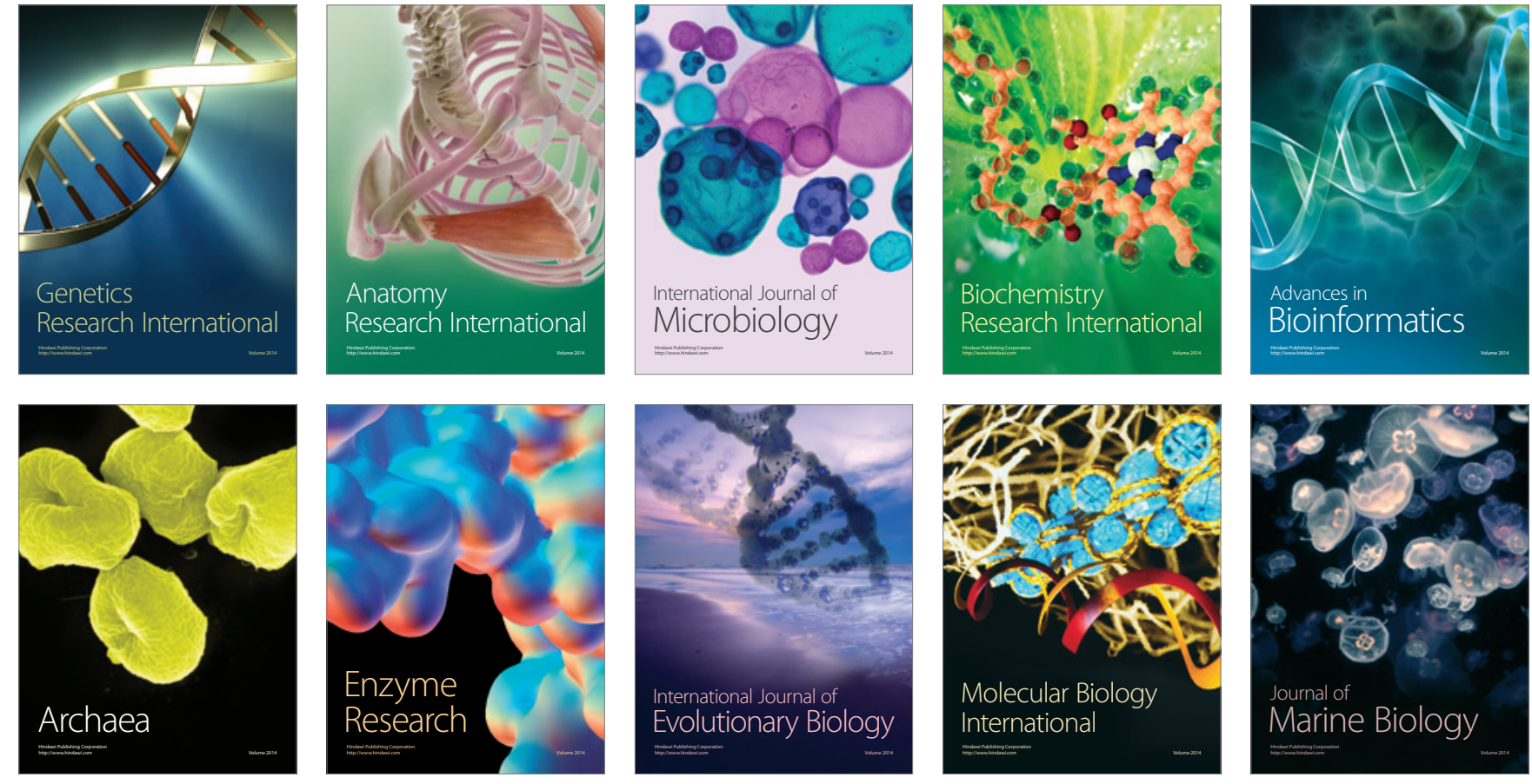